\title{
Do mental health disorders matter in pre- adolescents with cerebral palsy?
}

\author{
Bjorgaas $\mathrm{HM}^{1 *}$, Hysing $\mathrm{M}^{2}$ and Elgen $\mathrm{I}^{3}$ \\ ${ }^{1}$ Department of Child Neurology, Stavanger University Hospital, Stavanger, Norway \\ ${ }^{2}$ Department of Psychosocial Science, Faculty of Psychology, University of Bergen, Norway \\ ${ }^{3}$ Department of Child and Adolescent Psychiatry, Haukeland University Hospital, Norway
}

\begin{abstract}
Objective: To assess the rate of mental health disorders according to diagnostic criteria, in pre-adolescents with Cerebral Palsy (CP).

Design: Participants in this cohort study were 47 children with a diagnosis of CP, assessed at 11 years of age. They were born $2001-2003$ and living in the Western Health Region of Norway. The Kiddie-SADS, a child psychiatric, diagnostic instrument, was used for assessment of mental health disorders.

Results: Almost four in five children met diagnostic criteria for one or more mental health disorders. Of these children, two in three met criteria for behavioural disorder, one in three met criteria for anxiety disorder, and there was a considerable co-occurrence of disorders. No significant association was found between medical parameters and mental health disorders.
\end{abstract}

Conclusions: Mental health disorders are highly prevalent in pre-adolescents with CP in the present study, and we suggest that mental health assessment should be included as part of the regular follow-up of children with $\mathrm{CP}$.

\section{Introduction}

Increasing evidence has shown that mental health problems often co-occur with Cerebral Palsy (CP), causing distress for the child and family [1-5]. Although diagnostic criteria for $\mathrm{CP}$ are based on motor symptoms, a recent meta-analysis including eight studies of children and adolescents, found a $35 \%$ pooled prevalence of mental health problems in children with CP [6]. Despite several questionnaire based studies having found mental health problems highly prevalent in children with $\mathrm{CP}[1-3,7,8]$, there is to our knowledge only one previous study reporting on mental health disorders assessed using a diagnostic instrument [5]. In this study, we assessed children with $\mathrm{CP}$ at school starting age (7 years) and found that $57 \%$ of the participants met criteria for a child mental health disorder. The same prevalence was found across Gross Motor Function Classification System (GMFCS) levels I-IV, where GMFCS levels I describe mild disability. In this study, behavioural disorders were most common, and 50\% of the participants met criteria for Attention Deficit Hyperactivity Disorder (ADHD). In the same study, $10 \%$ of the children met criteria for emotional disorders (anxiety and affective disorders) [5]. While not included in the previous study of the current sample, other studies have found Autism Spectrum Disorder in one in seven children with CP $[9,10]$.

For mental health problems in adolescents with $\mathrm{CP}$, previous studies have been less conclusive. In a Canadian questionnaire-based study, there was a consistently high prevalence of mental health problems from childhood to adolescence $[11,12]$. On the other hand, a Dutch study found a diminishing trend for externalizing problems, while internalizing problems were stable over a three-year period as the children approached adolescence [13]. The need for more studies assessing the prevalence of mental health disorders according to diagnostic criteria in children and adolescents with $\mathrm{CP}$, was also highlighted in a recent meta-analysis [6]. Precise knowledge regarding the prevalence of mental health disorders using diagnostic criteria, seems of importance when planning holistic services and allocating specialist resources to young people with CP.

The aim of the present study is 1) to explore mental health disorders using a diagnostic instrument in pre-adolescents with $\mathrm{CP}$, and 2) to describe the outcome according to type of $\mathrm{CP}$, severity and co-existing medical conditions.

\section{Methods}

\section{Population}

All 98 children with CP born 2001-2003 and living in the Western Health Region of Norway were invited to take part in an assessment of mental health disorders at school starting age. Of these, parents of 67 children gave approval to participate, and were interviewed using the diagnostic instrument Kiddie-SADS. For children with GMFCS level V, the diagnostic instrument was found to be inappropriate due to severe motor impairment, often accompanied by intellectual disability (ID), severe spasms and communication problems, as described in a previous paper [5]. The Kiddie-SADS was found appropriate for children with GMFCS levels I-IV, comprising 56 children who were now invited to take part in a follow-up assessment four years later.

Correspondence to: Hanne Marit Bjorgaas, Department of Child Habilitation and Neurology, Stavanger University Hospital, Stavanger HF, Post box 8100, 4068 Stavanger, Norway, Tel: 47-98895956; E-mail: bjhm@sus.no

Key words: mental health disorders, cerebral palsy, behavioural disorders, anxiety

Received: February 25, 2019; Accepted: March 08, 2019; Published: March 13, 2018 


\section{Classification, functional levels, cognitive functioning and medical information}

Cerebral palsy was classified according to ICD-10 criteria G80.0-G80.9 with the following subgroups: Spastic bilateral and unilateral, dyskinetic, atactic or not further classified. We recorded status of classification given prior to the study and stated in the medical record.

Functional level was classified by the Gross Motor Function Classification System (GMFCS) which distinguishes five groups. Classification for gross motor function was based on self-initiated movement, functional limitations, and the use of mobility devices in everyday life. Functional classification given in the medical record was obtained, or classification was done, during the medical examination if information was not available prior to the study. In this study, we included mild and moderate disability. Classification was grouped as follows:

1. Mild disability, GMFCS I and II, normally without need for assistive walking devices.

2. Moderate disability, GMFCS III and IV, normally fully, or to some extent reliant on walking aid or wheelchair.

Children with severe disability, GMFCS level V, were not included in the study as described above. Information regarding type and severity of CP, co-existing conditions as well as demographic data was collected at school starting age, and any changes were recorded at age 11 [5].

Cognitive functioning was recorded through information in the medical record and verified by parents during the interview.

From the child's medical record, available information on communication difficulties, as well as information regarding epilepsy or other diagnoses was recorded at school starting age, when also a medical examination was done [5]. Any changes in the medical condition were recorded at age 11 .

\section{Mental health assessment instrument}

The Kiddie-SADS is a semi structured child and adolescent psychiatric diagnostic instrument used to ascertain mental health disorders according to DSM IV criteria [14]. Parents of children with CP were interviewed using the Kiddie-SADS (PL) 2009 version for ages 6-18, designed to unveil psychiatric symptoms within the following groups of disorders: affective-, anxiety-, psychotic-, eating-, attention/hyperactivity-, oppositional defiant-, conduct-, tics- substance abuse- and posttraumatic stress disorders, as well as autism spectrum disorders. Information on enuresis and encopresis was not included at age 11, due to a high level of uncertainty regarding the aetiology of these symptoms in children with CP [5]. Behavioural disorders include ADHD, ODD and Conduct disorders. Emotional disorders include Anxiety, OCD, Affective disorders and Tic disorders. All disorders within the autism spectrum were grouped as autism spectrum disorders (ASD). Given the semi-structured design of the kiddie-SADS, parents were asked to elaborate answers with information on the existence of mental health symptoms in different contexts, including home, school and leisure activities to ensure information regarding the consistency of symptoms. In this study, we have used the term mental health disorder for a condition where diagnostic criteria for a child psychiatric disorder was fulfilled, as opposed to mental health problems describing mental health symptoms without relating these directly to a diagnostic disorder.

\section{Statistical analysis}

Descriptive analyses were used to describe the prevalence of mental health disorders, and logistic regression was used to examine demographics, clinical characteristics and functional level when comparing children meeting criteria for a mental health disorder to those not meeting criteria for a disorder. For statistical analysis, SPSS version 24 was used.

\section{Results}

\section{Population, classification and co-morbid medical conditions}

In the present study, 56 children with GMFCS level I-IV were invited to participate. One child did not take part according to the wish of the parents, and another child did no longer meet diagnostic criteria for CP. Seven children were lost to follow-up. In the present study, parents of 47/56 (84\%) children took part, encompassing half of the population with a CP diagnosis born during 2001-2003, and living in the Western Health Region of Norway. Parents of these children were interviewed at pre-adolescence (age11), using the Kiddie-SADS child psychiatric diagnostic instrument. Characteristics, classification and functional level of the cohort are described in Table 1. Mean age was 132 months ( 11 years), and 60\% were boys.

\section{Prevalence of mental health disorders}

Criteria for one or more mental health disorders were met in $79 \%$ of the study population (Table 2), and prevalence rates are displayed in Table 2. Among children with behavioural disorders, ADHD 27/47 (57\%) was most frequent (Table 2). The inattentive sub type of ADHD was the most common, affecting 22/47 (47\%) children. When omitting children meeting criteria for ADHD, 10 children (21\%) still met criteria for one or more mental health disorders. The population characteristics were similar for children not meeting criteria for ADHD compared to the whole cohort, apart from finding that $38 \%$ had GMFCS levels III-IV when omitting $\mathrm{ADHD}$, compared to $23 \%$ in the whole cohort.

For children with emotional disorders, anxiety was most common, among which the sub classification phobic disorder was the most prevalent (Table 2).

Six children met criteria for ASD (Table 2), and all these children also met criteria for one or more additional mental health disorders (Table 3).

Table 1. Characteristic and co-occurring medical conditions in children with $\mathrm{CP}^{\mathrm{i}}$, GMFCS levels I-IV at ages

\begin{tabular}{|l|c|c|}
\hline $\mathbf{N}=\mathbf{4 7}$ & $\mathbf{N}$ & $\mathbf{\%}$ \\
\hline Gender & 28 & 59.6 \\
\hline Male & & \\
\hline CP subtype & 26 & 55.3 \\
\hline Bilateral & 16 & 34.0 \\
\hline Unilateral & 5 & 10.6 \\
\hline Ataxia/Dyskinesia & & \\
\hline GMFCS levels & 36 & 76.6 \\
\hline I+II & 11 & 23.4 \\
\hline III+IV & 9 & 19.6 \\
\hline Gestational age $<32$ weeks & 16 & 34.0 \\
\hline Intellectual Disability & 12 & 25.5 \\
\hline Epilepsy & 21 & 44.7 \\
\hline Communication problems & & \\
\hline
\end{tabular}

${ }^{i}$ Cerebral Palsy

${ }^{\mathrm{ii}}$ Gross Motor Function Classification System 
Table 2: Psychiatric disorders in children with $\mathrm{CP}$ at age 11

\begin{tabular}{|c|c|c|}
\hline $\mathbf{N}=\mathbf{4 7}$ & $\mathbf{N}$ & $\mathbf{\%}$ \\
\hline Any psychiatric disorder $^{\mathrm{i}}$ & 37 & 78.7 \\
\hline Any behavioural disorder & 31 & 66.0 \\
\hline ADHD & 27 & 57.4 \\
\hline ODD $^{\text {ii//Conduct disorder }}$ & 10 & 21.2 \\
\hline Any emotional disorder & 19 & 40.4 \\
\hline Affective disorder & 5 & 10.6 \\
\hline Anxiety disorders ${ }^{i i i}$ & 16 & 34.0 \\
\hline OCD & 5 & 10.6 \\
\hline General anxiety & 9 & 19.1 \\
\hline Phobic anxiety & 10 & 21.3 \\
\hline Separation anxiety & 3 & 6.4 \\
\hline Panic disorder & 3 & 6.4 \\
\hline Autism spectrum disorders & 2 & 12.8 \\
\hline Tic disorders & & 4.3 \\
\hline
\end{tabular}

${ }^{\mathrm{I}}$ Co-occurring disorders are highly prevalent

ii Oppositional Defiant Disorder

iii Number of children with any anxiety disorders, type of disorder is further specified below

Table 3. Co-occurring psychiatric disorders in children with CP age 11

\begin{tabular}{|c|c|}
\hline $\mathbf{N = 4 7}$ & $10(21 \%)$ \\
\hline No psychiatric disorder & $13(28 \%)$ \\
\hline Behavioural disorders only & $5(11 \%)$ \\
\hline Emotional disorders only & $13(28 \%)$ \\
\hline $\begin{array}{c}\text { Butism Spectrum Disorders with Emotional and/or Behavioural disorders } \\
\text { combined }\end{array}$ & $6(13 \%)$ \\
\hline
\end{tabular}

\section{Medical characteristics}

We found no associations between meeting criteria for mental health disorders and gender, co-occurring medical conditions, type of $\mathrm{CP}$ or functional level (Table 4).

\section{Discussion}

In a Norwegian population including 47 children with $\mathrm{CP}$ at preadolescence (age11), three in four children met criteria for a mental health disorder. Behavioural disorders were the most prevalent, affecting two in three children, whereas emotional disorders affected two in five children. We found Autism Spectrum Disorder (ASD) in one in eight children, and a considerable overlap of mental health disorders. Neither type of CP, severity of the condition nor co-occurring medical conditions increased the odds of having a mental health disorder.

\section{Mental health disorders}

The prevalence of mental health disorders in the present study by far exceeded that of seven percent reported in a Norwegian population based study of 8-10 year old children [15], and the estimated pooled prevalence of $35 \%$ in a recent meta-analysis of mental health in children with CP [6]. Perhaps the high prevalence of mental health disorders was related to the nature of a semi- structured interview, which allows for elaboration of answers and assessment according to diagnostic criteria. For instance, we found many parents had not recognized attention problems and distractibility. Spending hours next to their child during home- work sessions were ingrained in their everyday life, and these symptoms would perhaps not have been captured in a questionnaire.

\section{Behavioural disorders}

Behavioural disorders were the most common, especially attention problems, of which the subgroup without hyperactivity encompassed 22/27 children. This subgroup can be difficult to capture, as symptoms may be less visible, however the impact on learning and the development of social relations may be considerable [16]. Previous studies have described attention problems in a wide range of other neurological disorders $[1,5,7,17]$, such as in a Dutch study concluding that $39 \%$ of children with neurological disorders had ADHD. In this particular study, less than a third of children with neurological disorders had been diagnosed with ADHD previously. This indicates that ADHD may have been overshadowed by the somatic or syndrome related features of the neurological disorder, emphasizing the importance of offering multi-disciplinary assessments of children with attention problems and neurological disorders [17]. A proactive approach towards ADHD with or without hyperactivity could perhaps improve quality of life and enhance the learning environment for these children. Proactive measures could include school-related adaptations as well as the use of medication, which in a previous study has shown positive effects in children with CP [18]. Further, in these children, differentiating between inattention due to ADHD and epilepsy may be a clinical challenge. Distinguishing the two disorders is however of importance, as medical treatment would differ. Striving to classify mental health disorders correctly seems of importance for health planners to allocate resources to the level of care responsible for these disorders in children and adolescents with CP.

\section{Emotional disorders}

Emotional disorders were prevalent in $40 \%$, exceeding that of $3 \%$ in a Norwegian population study of children ages 8-10 [15], and in line with questionnaire based studies $[2,8,12]$. Generalized anxiety and phobic anxiety were most common, and there was a considerable overlap of different anxiety disorders. For some children with $\mathrm{CP}$, an increased awareness of their own shortcomings may have become more apparent by pre-adolescence, after having been exposed to increasing demands related to school performance, leisure activities, peer relationships as well as motor skills. An incongruence between demands or expectations, and the developmental level of the child, may pose an increased risk for psychopathology [19]. On the other hand, the high prevalence of emotional disorders could be related to intrinsic factors, such as difficulties understanding social codes of conduct or subtle social cues from peers.

\section{Autism spectrum disorder}

ASD was reported in six children in the present study (13\%), of whom all met criteria for co-occurring behavioural and/or emotional disorders. Increased prevalence of ASD in children with CP has also been described in a recent register study [9], with considerable variation in prevalence rates across regions, perhaps suggesting differences in diagnostic practices. To our knowledge, only one previous clinical study has used an ASD diagnostic assessment tool in children with CP

Table 4. Children with $\mathrm{CP}$ meeting criteria for a psychiatric disorder at age 11 according to medical characteristics. Criteria for one or more psychiatric disorders were met in 37 children

\begin{tabular}{|c|c|c|c|}
\hline$N=47$ & $\mathbf{N}$ & OR & $95 \% \mathrm{CI}$ \\
\hline Boys & $22 / 37$ & 1.0 & $0.2-4.1$ \\
\hline Intellectual disability & $17 / 37$ & 3.4 & $0.6-18.2$ \\
\hline Epilepsy & $7 / 37$ & 2.2 & $0.2-20.1$ \\
\hline Speech problems & $17 / 37$ & 1.3 & $0.3-5.3$ \\
\hline GMFCS $^{i}$ I-IV ${ }^{i i}$ & $10 / 37$ & 3.3 & $0.4-29.8$ \\
\hline Bilateral $^{\text {lii }} \mathrm{CP}$ & $26 / 37$ & 2.4 & $0.6-9.8$ \\
\hline Unilateral CP & $11 / 37$ & 0.4 & $0.1-1.8$ \\
\hline
\end{tabular}

${ }^{\mathrm{i}}$ Gross Motor Function Classification System

${ }^{i i}$ GMFCS levels III-IV, assessed against GMFCS levels I-II

iiiBilateral $\mathrm{CP}$ including ataxia and dyskinesia, and assessed against unilateral $\mathrm{CP}$ 
[10]. In this study, $15 \%$ met criteria for an ASD, similar to our findings. All children with an ASD in the present study had co-occurring behavioural and /or emotional disorders, such as in a British study of children with ASD [20], in which co-occurring mental health disorders were found in $72 \%$.

\section{Co-occurring behavioural and emotional disorders}

Co-occurring behavioural and emotional disorders were found in almost one in three children, and we are faced with a challenge in identifying mental health disorders as well as differentiating these disorders from co-existing medical conditions in children with CP [21]. Recognizing mental health disorders in children with CP and ID or communication problems often impose challenges, even if the diagnosis of CP itself is rather clear-cut. The prevalence of co-occurring mental health disorders ranges from $10-80 \%$ in children with ID [22-24], and occurs in $37 \%$ of children with epileptic disorders [25], as opposed to a prevalence ranging from $7-15 \%$ in the general childhood population $[15,26,27]$. Increased focus on cross-disciplinary paediatric and mental health follow- up of children with CP and other neurological conditions seems of importance, as recent research have found a similarly high prevalence of behavioural problems in adults as in children with $\mathrm{CP}$ [28].

We did not find an association between mental health disorders and gender, subtype of $\mathrm{CP}$, severity of the condition or co-occurring medical disorders, in accordance with a Canadian questionnaire based study including school-aged children with CP [12]. Based on previous literature, we expected a higher rate of mental health disorders in children with ID [22], however this was not supported in the present study. Perhaps children less severely affected by CP face challenges in their interaction with otherwise healthy peers more often than those severely affected. In fact, a previous multicentre study found a higher score on mental health problems associated with better cognitive abilities and less severe CP [2]. Lack of association between mental health disorders and medical conditions could however also be due to lack of statistical power to detect differences in the smaller subgroups. A previous study did for instance find ASD associated with male gender, ID, epilepsy, and better walking ability in children with CP [9].

\section{Methodological strengths and challenges}

The present study is to our knowledge unique in its use of a child mental health diagnostic instrument in pre-adolescents with $\mathrm{CP}$, allowing for elaboration of answers in order to differentiate symptoms in complex conditions such as CP. Further, all interviews were conducted by a child- and adolescent psychiatrist, and some of the interviews were recorded and assessed by a second child psychiatrist for quality assurance. There are however several limitations to the study, as we have only interviewed parents of children with CP. Interviews with teachers as well as self-report interviews could perhaps have given a more complete picture regarding mental health disorders. Further, children with GMFCS levels V was excluded, as the Kiddie-SADS was inappropriate as a diagnostic instrument for the most severely affected children. For further studies, a more appropriate instrument should perhaps be used to assess mental health in these children. Regrettably, the study had an attrition rate of $16 \%$ compared to the cohort assessed using a diagnostic instrument at school starting age. The cohort was however representative regarding demographic and medical characteristics for children with GMFCS levels I-IV. We found a slightly higher prevalence of children with ID in the pre-adolescence cohort, perhaps related to more children having been tested and recognized as having ID by that age.

\section{Implications}

Three in four pre-adolescents with CP met criteria for a mental health disorder, with a high prevalence of co-occurring disorders. Addressing mental health needs alongside the medical needs in children with CP seems of importance, as well as adapting services to the specific needs of children and young people with CP. Further research until young adulthood seems of importance to develop multidisciplinary services including mental health in a longitudinal perspective.

\section{Acknowledgements}

We want to thank the children and the parents participating in this study. The research has been funded by the Western Health Region Research Funding, Norway.

\section{References}

1. Sigurdardottir S, Indredavik MS, Eiriksdottir A, Einarsdottir K, Gudmundsson HS, et al. (2010) Behavioural and emotional symptoms of preschool children with cerebral palsy: a population-based study. Dev Med Child Neurol 52: 1056-1061. [Crossref]

2. Parkes J, White-Koning M, Dickinson HO, Thyen U, Arnaud C, et al. (2008) Psychological problems in children with cerebral palsy: a cross-sectional European study. J Child Psychol Psychiatry 49: 405-413. [Crossref]

3. Parkes J, White-Koning M, McCullough N, Colver A (2009) Psychological problems in children with hemiplegia: a European multicentre survey. Arch Dis Child 94: 429433. [Crossref]

4. Parkes J, Caravale B, Marcelli M, Franco F, Colver A (2011) Parenting stress and children with cerebral palsy: a European cross-sectional survey. Dev Med Child Neurol 53: 815-821. [Crossref]

5. Bjorgaas HM, Hysing M, Elgen I (2012) Psychiatric disorders among children with cerebral palsy at school starting age. Res Dev Disabil 33: 1287-1293. [Crossref]

6. Downs J, Blackmore AM, Epstein A, Skoss R, Langdon K, et al. (2018) The prevalence of mental health disorders and symptoms in children and adolescents with cerebral palsy: a systematic review and meta-analysis. Dev Med Child Neurol 60: 30-38. [Crossref]

7. Bjorgaas HM, Elgen I, Boe T, Hysing M (2013) Mental health in children with cerebra palsy: does screening capture the complexity? Scientific World Journal 2013: 468402. [Crossref]

8. Ramstad K, Jahnsen R, Skjeldal OH, Diseth TH (2012) Mental health, health related quality of life and recurrent musculoskeletal pain in children with cerebral palsy 8-18 years old. Disabil Rehabil 34: 1589-1595. [Crossref]

9. Delobel-Ayoub M, Klapouszczak D, van Bakel MME, Horridge K, Sigurdardottir S, et al. (2017) Prevalence and characteristics of autism spectrum disorders in children with cerebral palsy. Dev Med Child Neurol 59: 738-742. [Crossref]

10. Kilincaslan A, Mukaddes NM (2009) Pervasive developmental disorders in individuals with cerebral palsy. Dev Med Child Neurol 51: 289-294. [Crossref]

11. Brossard-Racine M, Waknin J, Shikako-Thomas K, Shevell M, Poulin C, et al. (2013) Behavioural difficulties in adolescents with cerebral palsy. J Child Neurol 28: 27-33. [Crossref]

12. Brossard-Racine M, Hall N, Majnemer A, Shevell MI, Law M, et al. (2012) Behavioura problems in school age children with cerebral palsy. European journal of paediatric neurology: EJPN: official journal of the European Paediatric Neurology Society 16: 35-41. [Crossref]

13. Sipal RF, Schuengel C, Voorman JM, Van Eck M, Becher JG (2010) Course of behaviour problems of children with cerebral palsy: the role of parental stress and support. Child Care Health Dev 36: 74-84. [Crossref]

14. Kaufman J, Birmaher B, Brent D, Rao U, Flynn C, et al. (1997) Schedule for Affective Disorders and Schizophrenia for School-Age Children-Present and Lifetime Version (K-SADS-PL): initial reliability and validity data. J Am Acad Child Adolesc Psychiatry 36: 980-988. [Crossref]

15. Heiervang E, Stormark KM, Lundervold AJ, Heimann M, Goodman R, et al. (2007) Psychiatric disorders in Norwegian 8- to 10-year-olds: an epidemiological survey of prevalence, risk factors, and service use. J Am Acad Child Adolesc Psychiatry 46: 438447. [Crossref] 
16. Bottcher L, Flachs EM, Uldall P (2010) Attentional and executive impairments in children with spastic cerebral palsy. Dev Med Child Neurol 52: e42-47. [Crossref]

17. Hendriksen JGM, Peijnenborgh JCAW, Aldenkamp AP, Vles JSH (2015) Diagnostic overshadowing in a population of children with neurological disabilities: A cross sectional descriptive study on acquired ADHD. Eur J Paediatr Neurol 19: 521-524. [Crossref]

18. Gross-Tsur V, Shalev RS, Badihi N, Manor O (2002) Efficacy of methylphenidate in patients with cerebral palsy and attention-deficit hyperactivity disorder (ADHD). $J$ Child Neurol 17: 863-866. [Crossref]

19. Bottcher L, Dammeyer J (2013) Disability as a risk factor? Development of psychopathology in children with disabilities. Res Dev Disabil 34: 3607-3617. [Crossref]

20. Simonoff E, Pickles A, Charman T, Chandler S, Loucas T, et al. (2008) Psychiatric disorders in children with autism spectrum disorders: prevalence, comorbidity, and associated factors in a population-derived sample. J Am Acad Child Adolesc Psychiatry 47: 921-929. [Crossref]

21. Bax M, Goldstein M, Rosenbaum P, Leviton A, Paneth N, et al. (2005) Proposed definition and classification of cerebral palsy, April 2005. Dev Med Child Neurol 47: 571-576. [Crossref]
22. Borthwick-Duffy SA1 (1994) Epidemiology and prevalence of psychopathology in people with mental retardation. J Consult Clin Psychol 62: 17-27. [Crossref]

23. Emerson E (2003) Prevalence of psychiatric disorders in children and adolescents with and without intellectual disability. J Intellect Disabil Res 47: 51-58.

24. Einfeld SL, Ellis LA, Emerson E (2011) Comorbidity of intellectual disability and mental disorder in children and adolescents: a systematic review. $J$ Intellect Dev Disabil 36: 137-143. [Crossref]

25. Davies S, Heyman I, Goodman R (2003) A population survey of mental health problems in children with epilepsy. Dev Med Child Neurol 45: 292-295. [Crossref]

26. Costello EJ, Mustillo S, Erkanli A, Keeler G, Angold A (2003) Prevalence and development of psychiatric disorders in childhood and adolescence. Arch Gen Psychiatry 60: 837-844. [Crossref]

27. Meltzer H, Gatward R, Goodman R, Ford T (2000) Mental health of children and adolescents in Great Britain. Int Rev Psychiatry 15: 185-187. [Crossref]

28. Weber P, Bolli P, Heimgartner N, Merlo P, Zehnder T, et al. (2016) Behavioral and emotional problems in children and adults with cerebral palsy. Eur J Paediatr Neurol 20: 270-274. [Crossref]

Copyright: (C2019 Bjorgaas HM. This is an open-access article distributed under the terms of the Creative Commons Attribution License, which permits unrestricted use, distribution, and reproduction in any medium, provided the original author and source are credited. 